\title{
Tapuy miri, chiquitos, chiquitanos. Historia de un nombre en perspectiva interétnica
}

Tapuy miri, chiquitos, chiquitanos. Histoire d'un nom en perspective interethnique

Tapuy miri, Chiquitos, Chiquitanos. The History of a Name from an Interethnic Viewpoint

\section{Cecilia Martínez}

\section{OpenEdition}

\section{Journals}

Edición electrónica

URL: http://journals.openedition.org/bifea/7525

DOI: $10.4000 /$ bifea. 7525

ISSN: 2076-5827

\section{Editor}

Institut Français d'Études Andines

\section{Edición impresa}

Fecha de publicación: 1 agosto 2015

Paginación: 237-258

ISSN: 0303-7495

\section{Referencia electrónica}

Cecilia Martínez, «Tapuy miri, chiquitos, chiquitanos. Historia de un nombre en perspectiva interétnica », Bulletin de l'Institut français d'études andines [En línea], 44 (2) | 2015, Publicado el 13 noviembre 2015, consultado el 05 noviembre 2020. URL : http://journals.openedition.org/bifea/7525 ; DOI : https:// doi.org/10.4000/bifea.7525

\section{(c) $(1) \odot$}

Les contenus du Bulletin de l'Institut français d'études andines sont mis à disposition selon les termes de la licence Creative Commons Attribution - Pas d'Utilisation Commerciale - Pas de Modification 4.0 International. 


\title{
Tapuy miri, chiquitos, chiquitanos. Historia de un nombre en perspectiva interétnica
}

\author{
Cecilia Martínez*
}

\section{Resumen}

Habitualmente los chiquitanos son identificados como los herederos de la cultura misional jesuítica, aunque su nombre y su situación sociocultural variaron tanto antes como después de ese período. «Chiquitos», por su parte, encabeza una familia de conceptos étnicos, topográficos, lingüísticos e identitarios que se construyeron y transformaron desde el siglo XVI hasta la actualidad. Reconstruir el derrotero de la etnonimia de los indígenas de la Chiquitania y de los significados asociados con ella es el objetivo de este trabajo, guiado por la premisa del papel central que ocupan las relaciones con otros grupos indígenas y con los blancos en la definición de la forma y del contenido de los grupos y de sus designaciones recíprocas.

Palabras clave: chiquitos, chiquitano, etnonimia, relaciones interétnicas, etnohistoria, Oriente boliviano

\section{Tapuy miri, chiquitos, chiquitanos. Histoire d'un nom en perspective interethnique}

\section{Résumé}

Les chiquitanos sont généralement vus comme les héritiers de la culture des missions jésuites, alors que leur nom et leur situation socio-culturelle ont subi des variations d'une époque à l'autre. La notion même de «Chiquitos » renvoie à une série de concepts ethniques, topographiques, linguistiques et identitaires qui se sont construits et ont évolué depuis le XVIe siècle jusqu'à nos jours. Retracer le parcours de l'ethnonyme des Indiens de la région de Chiquitos est l'objectif de ce travail, à partir 
de l'idée que les relations inter-ethniques jouent un rôle central dans la définition de la forme et du contenu des groupes et de leurs divers noms.

Mots-Clés : chiquitos, chiquitano, ethnonyme, relations inter-ethniques, ethnohistoire, Orient bolivien

\title{
Tapuy miri, Chiquitos, Chiquitanos. The History of a Name from an Interethnic Viewpoint
}

\begin{abstract}
The Bolivian Chiquitano are often identified as inheritors of Jesuit culture, although their name and sociocultural situation changed greatly before and after the missionary period. The term "Chiquitos" evokes a family of ethnic, topographic, linguistic and identity concepts built and transformed since the 16th century. The aim of this essay is to reconstruct both the origin and changes in the naming of the Chiquitano peoples, and the different meanings associated with them. The analytical premise is the central role played by the ethnic relations with other native groups as well as with the White people, and its importance for the definition of the form and content of these groups and their names.
\end{abstract}

Keywords: Chiquitos, Chiquitano, Ethnonyms, Interethnic relations, Ethnohistory, Eastern Bolivia

\section{EL NOMBRE Y EL PUEBLO}

En la actualidad chiquitano es el nombre del pueblo indígena más numeroso de Bolivia después del quechua y aymara1. El etnónimo, de raíz y terminación castellanas, encierra —_de forma más transparente en este caso pero no menos presente en otros de origen nativo - una larga historia de relaciones interétnicas. Porque, en efecto, el acto de nombrar es inherente a las relaciones sociales. Aun si se trata de un ejercicio reflexivo, un grupo de personas que se autodenomina se delimita frente a otros de la misma manera que, al designar con un nombre a otro grupo, lo define en relación consigo mismo y entonces deslinda su propia identidad. Pero, además, dado que cada acto de nominación es relacional, es también situacional, relativo en función del tiempo y del espacio y por lo tanto, sociohistórico. Por eso los nombres de los pueblos cuentan historias: la de las relaciones entre quienes nombran y son nombrados pero también la de quienes bajo el mismo rótulo de un nombre adoptado o impuesto van cambiando de posición y variando el contenido del significante. El carácter polisémico que adquiere el término «chiquitos» y la serie de conceptos étnicos, topográficos,

1 Según los resultados del último censo nacional de población y vivienda 87885 (45 497 hombres y 42388 mujeres) chiquitanos viven en Bolivia, 1281116 quechuas y 1191352 aymaras (Instituto Nacional de Estadística, 2012: 31). 
lingüísticos e identitarios asociados con él invitan a repasar los significados que son puestos en juego desde su origen hasta la actualidad. En el decurso los «exónimos» se vuelven «endónimos», los etnónimos pasan a ser topónimos, estos derivan en gentilicios —chiquitano, al igual que mojeño, cavineño o joaquiniano-, y en nombres de pueblos indígenas 2 . Reconstruir el derrotero de la etnonimia de los indígenas de la Chiquitania y de los significados asociados con ella es el objetivo de este trabajo, guiado por la premisa del lugar central que ocupan las relaciones con otros grupos indígenas y con los blancos en la definición de la forma y del contenido de los grupos y de su onomástica.

Esta reflexión en torno a la etnonimia está inspirada en los trabajos de Barth (1976) y Cardoso de Oliveira (2003 [1971]) sobre la definición de los grupos étnicos, especialmente en la idea del carácter relacional y de la variación de su delimitación y de su composición, asociada con las transformaciones que ocurren en el plano de las relaciones interétnicas. Pero grupo y nombre no son considerados problemas equivalentes aquí, donde lo que se analiza es evidencia escrita en la que los nombres no suelen corresponderse necesariamente con autodenominaciones $y$, por lo tanto, no están asociados con criterios de autoadscripción. Ello no inhibe, sin embargo, la posibilidad de intentar una aproximación al actor indígena involucrado en estas relaciones de nominación a través de la reconstrucción de la genealogía del etnónimo, más aún cuando en este pasado se encuentra el origen del nombre con el que actualmente se identifican los chiquitanos.

La historia comienza en el siglo XVI con las primeras crónicas y registros de los conquistadores que exploraron la región desde el Paraguay en dirección al piedemonte andino, en las que ya aparece la marca de la mediación guaraní en la nominación de los chiquitos. Continúa con la llegada de los jesuitas a la región, la aplicación de nuevos parámetros políticos, culturales y sociales a la lectura de su composición étnica y la diversificación de los usos del etnónimo quinientista chiquitos. Una doble dimensión fronteriza impresa durante la administración borbónica sobre los indígenas de la región cierra el tramo colonial, mientras que el período republicano se inaugura con los aportes del naturalista francés Alcide d'Orbigny, imitado luego por numerosos exploradores, misioneros y etnográfos cuyos registros ayudan a reconstruir los movimientos y cambios protagonizados por la población a lo largo de todo el siglo XIX y sus implicancias socioculturales. El recorrido se completa con el proceso de comunalización del siglo XX, que salpicó la región de ranchos, comunidades y pueblos.

2 Todos ejemplos de «misiónimos» siguiendo el concepto acuñado por Francis Ferrié (2013) en su tesis reciente sobre los lecos del piedemonte de Apolobamba a Larecaja. 


\section{2. «TAPIOMIRI QUE LOS ESPAÑOLES ABREVIANDO LOS LLAMAN CHIQUITOS»}

Según la evidencia más temprana, en el siglo XVI los chiquitos eran un grupo de indígenas que vivían al oeste de los xarayes, más allá de los etones, pamonos y jaramecocíes con quienes los asunceños e indios amigos guaraníes de la expedición de Ñuflo de Chaves, que salió de Asunción en 1557, mantuvieron violentas escaramuzas (Relación de los casos..., 2008 [1561]: 68). También se les ubicó junto a los chiriguanaes de Pitaguari, a cuarenta y cinco leguas al norte de Santa Cruz la Vieja y a treinta leguas de donde había sido fundada La Barranca; fueron repartidos entre los españoles de Santiago del Puerto a partir de 1592 y luego entre los vecinos de San Lorenzo y su verdadero nombre era tovaçicoçi (Relación verdadera..., 2008 [1571]: 216; Relación del P. Diego de Samaniego, 1944 [c. 1600]: 488). Los guaraníhablantes les llamaban «tapiomiri que quiere decir esclavos de casas chicas, y los españoles abreviando los Ilaman chiquitos») (Relación del P. Diego de Samaniego, 1944: 488). Aunque la traducción del nombre en guaraní, asociada con el tamaño de sus casas, fue la más difundida entre los cronistas contemporáneos y entre los expedicionarios y misioneros posteriores, no es la única interpretación posible: los guaraníes pudieron haberse referido a los «esclavos chicos», en consonancia con las categorías que utilizaban para nombrar, clasificar a e interactuar con grupos no guaraníes: tapii, tapiete, tapuy mirí (Combès, 2010: 128, 280, 281). En efecto, según el relato del P. Samaniego, al sugerirles a los guaraníes que vivían con los chiquitos que fueran a residir a Santa Cruz, respondieron «dejanos aqui capitan que nosotros trataremos a estos esclavos de suerte que nos sirvan bien» (Relación del P. Samaniego, 1944: 485). La evidencia sobre la relación entre chiquitos y guaraníhablantes de siglos posteriores abona esta hipótesis sobre la que volveremos luego. Por ahora basta con agregar que Ñuflo de Chaves y sus hombres entre 1557 y 1559 atravesaron la tierra de los tapuymire, gente muy guerrera, que usaba flechas envenenadas, que tenía un pueblo sobre un río y más adelante un cercado custodiado por muchos hombres preparados para la guerra. Alternaron acuerdos de paz con duros enfrentamientos bélicos en los que mataron hombres y caballos con la hierba ponzoñosa de sus flechas (Memoria y resolución..., 2008 [1560]: 54).

Tenemos entonces tres nombres en danza: tapuymiri, chiquitos y tovaçicoçi, de los que parece desprenderse una correspondencia entre quienes los guías guaraníes llamaban tapuymiri y los que los españoles llamaban chiquitos. Sin embargo, aunque el referente haya sido el mismo, en el proceso de traducción y adaptación del nombre se transformó su significado: «esclavo chico» pasó a significar «casa chica» y el contenido relacional e incluso contrastivo del nombre tapuymiri se diluyó — destino de confusión y metamorfosis no poco frecuente de los nombres indígenas asignados desde afuera 3 - Por otra parte, la calificación de tovaçicoçi como «el verdadero nombre» de los chiquitos hace sospechar que se trata de

3 Al respecto véase por ejemplo Combès, 2010: 21-28; Richard, 2011; Villar \& Combès, 2012 : 13-14. 
una forma de autodenominación. Cabe preguntarse entonces si todos aquellos que eran llamados tapuymiri por los guaraníes y chiquitos por los españoles, se llamaban a sí mismos tovaçicoçi o, dicho de otro modo, cuál fue el criterio a partir del que los españoles, que revelaron esta «verdadera» identidad, tomaron ambos nombres como análogos. Dado su origen heterogéneo resulta improbable que los patrones de nominación aplicados para tapuymiri hayan coincidido exactamente con los de tovaçicoçi y que por lo tanto ambos nombres se refieran, sin más, al mismo grupo de personas. El problema en definitiva es el de la definición del ser tapuymiri o chiquito y la del ser tovaçicoçi. Para el caso de tapuymiri es claro que lo que está en juego es cierto aspecto concerniente a la identidad de los guaraníhablantes que contrasta con la condición de esclavo, es decir, el hecho de ser libre o sin dueño pero también con la condición de indio que no habla guaraní y por lo tanto, de estatus inferior (Giannecchini, 1996 [1898]; Susnik, 1968; Combès \& Saignes, 1991). Chiquito, como fue dicho, parece ser una traducción y una adaptación al castellano del apelativo guaraní. Tovaçicoçi, por su parte, no resulta tan claro. Mientras que el sufijo -coçi es una marca del plural generalizada en la región en el siglo $\mathrm{XVI} 4$, la raíz tovaçica podría remitir a otubacis (Falkinger \& Tomichá, 2012b: 508) o tubasika (Parapaino citado en Combès, 2010: 298), que significa «patos» pero también a tubaxi-O-s (Adam \& Henry, 1895: 122) tubarschio o tubarschisch (Riester, 1986: 396) o itubaixica (Falkinger \& Tomichá, 2012b: 456): «ser molido», «moler» o «harina». Los patos, los molidos, los que muelen —o los de los morteros—-, los de la harina, son nombres que poco dicen en sí mismos. Pero si se los considera junto con los totaicoçi5, los borocoçí, los quibichicoçi7, los tavicoçis y tantos otros nombres que los asunceños y cruceños registraron en el siglo XVI entre quienes habitaban la gran área que se extiende entre los ríos Paraguay y Guapay y entre los $16^{\circ}$ y los $20^{\circ}$ de latitud sur, el horizonte se amplía. Probablemente estos nombres hicieran referencia a características del lugar donde vivía cada uno de estos grupos, a actividades productivas que los distinguían, a su temperamento o al nombre de sus jefes, en fin, a algún tipo o criterio de clasificación. Es difícil tener certeza de a cuál de estos marcadores - $\mathrm{O}$ a cuáles otros - obedecían estos nombres; la deducción a partir de las similitudes

4 Acerca del fenómeno sociodemográfico del que podría dar cuenta la difusión del sufijo -coci entre los nombres indígenas de Santa Cruz la Vieja y su entorno en el siglo XVI, Catherine Julien (2006) lo asoció con un posible origen o influencia zamuca, a partir de la similitud que encontró entre esta desinencia y la del singular gosi entre los ayoreo contemporáneos. Combès, por su parte, lo interpretó como evidencia de la chiquitanización de la región (Combès, 2006), producto de una posible combinación entre el chiquito y la lengua de los gorgotoqui que poblaban los alrededores de Santa Cruz la Vieja, tal vez de origen otuqui (Combès, 2012).

5 Podría derivar de totai- otutaína, palmera (Riester, 1986: 80, 76).

6 Siguiendo la raíz bororsch, significa elevaciones pero también ronchas o tumores. Por otra parte el nombre del toborochi, un árbol típico de la Chiquitania que se caracteriza por tener un tronco panzón entre el suelo y las ramas, podría derivar de esta raíz (Riester, 1986: 257).

7 Kübükisch o kibukis es bejuco o enredadera, raíz que también remite a dar la vuelta o a arquear (Riester, 1986: 285).

8 Según Tomichá (2002: 245), el nombre de los tavica, grupo del siglo XVIII que podría compartir la raíz de su nombre con los tavicoçi (Combès, 2010: 284), derivaría de la palabra que significa muerte o matanza en chiquito. 
que ellos guardan con otros registrados por los jesuitas un siglo y medio después, haciendo uso de los vocabularios de la lengua chiquita elaborados por padres de la Compañía y de los diccionarios contemporáneos de béstro (que es el nombre con el que actualmente se conoce la lengua chiquita) no puede resultar más que una aproximación. Sin embargo, es posible imaginar que los nombres aludidos más arriba pudieron haber funcionado como marcas de distinción entre grupos que se encontraban mancomunados por vivir en el mismo lugar, hablar lenguas similares, mantener comunicación e intercambios fluidos entre sí o por todo eso a la vez.

La omnipresencia del sufijo -coçi en los nombres de los grupos que habitaban la región donde el chiquito o algún otro idioma influido por aquel se impuso como lingua franca (Combès, 2010: 38), abona la idea de la «chiquitanización», descrita por Branislava Susnik como un proceso de «integración sociolingüística» para subrayar el carácter progresivo, incruento, sutil y tal vez indirecto que lo distinguiría de una invasión (Susnik, 1978: 36-38; cf. Tomichá, 2006). Los chiquitos difundieron su lengua en un lugar transitado y habitado por grupos de procedencias variadas que entretejían vínculos de diverso carácter - alianzas, guerras, intercambio de objetos- entre sí. La metáfora de la efervescencia ${ }^{9}$ para describir el escenario étnico de la región en el siglo XVI parece ser la más adecuada a la hora de dar cuenta de un espacio signado por desplazamientos, fusiones, préstamos e interacciones entre quienes lo habitaban, de su dinamismo sociocultural y demográfico provocado por las migraciones guaraníes y españolas del siglo XVI y por otras preexistentes en parte motivadas por las comunicaciones y transacciones en torno al tráfico de objetos de plata (Combès, 2008a). En un contexto de semejante movilidad y dinamismo, hacer distinciones etnolingüísticas tajantes de los grupos que lo habitaban es una quimera. Movilidad, por otra parte, acentuada en las décadas posteriores a las primeras exploraciones españolas por las expediciones esclavistas de los cruceños desde el oeste y de los bandeirantes portugueses desde el oriente. La falta de evidencia y el destino fatal de muchos de sus habitantes nativos hacen del siglo XVII una página sombría en la historia de la región.

\section{CHIQUITOS: LENGUA, NACIÓN Y PROVINCIA}

En la pluma de los jesuitas que llegaron a la región en el umbral del siglo XVIII, chiquitos —ahora también Chiquitos - cobró autonomía y asumió nuevos significados. Los padres de la Compañía de Jesús les asignaron un rótulo a los indígenas de la región a partir de sus propias concepciones políticas, sociales y culturales, e inmovilizaron en el nombre una realidad que estaba en plena ebullición. Paradójicamente, la chiquitanización previa de la región preparó el terreno para considerar parte de la misma nación a quienes hablaban la misma

9 «Efervescencia étnica» y desplazamientos hacia el sur de Chiquitos por la presión de los pueblos de las llanuras de Mojos es el panorama de la región que describió Susnik, en el que los nombres de desinencia -coci compartían el espacio con otros de la rama -ono arawak, chanés, otuquis y zamucos (Susnik, 1978: 44-45). 
lengua, criterio que, por otra parte, los eruditos de la orden consideraban parte de la naturaleza humana más que una invención de la literatura (Hervás \& Panduro, 1800: 3). Entonces chiquitos adquirió un sentido lingüístico. No obstante, los cuatro dialectos que distinguieron — tao, piñoco, peñoqui y manasi- son la prueba del dinamismo que seguía caracterizando a la región. La notable diferencia del dialecto peñoqui — que primaba entre los indios reducidos en la misión de San José- con respecto a los demás (y fundamentalmente al tao, que es el que se utilizó para la evangelización en todas las reducciones), ameritó la redacción de un vocabulario propio por parte del P. Felipe Suárez y dio pie a una hipótesis sobre la influencia del chiquito en los grupos de habla otuqui conocidos como gorgotoquis en el siglo XVI (Combès, 2012). De la misma manera puede interpretarse la dificultad para clasificar el dialecto manasi entre las lenguas chiquitas por su similitud con la lengua hablada por grupos arawak y por la cercanía de los manasihablantes —reducidos en la misión de Concepción, la más septentrional de Chiquitoscon la región de Mojos (Fernández, 1895 [1726]: 262; Suma das consultas..., 1955: 117; Métraux, 1942: 127). En el interior de cada grupo dialectal los jesuitas también identificaron las «tribus» en las que se dividían. Terminados ahora con el sufijo del dialecto tao -ca, aparecen nombres que recuerdan a los del siglo $\mathrm{XVI}$ que mencionamos más arriba: tubacica (tovaçicoçi), totaica (totaicoçi), boros (borocoçi), quibiquica (quibichicoçi), tabiica (tavicoçi), motaquica (motaquicoçi). Además, en las reducciones fueron integrados otros grupos que hablaban lenguas de otras familias y, por lo tanto, pertenecientes a otras «naciones» (léase que hablaban lenguas de otras familias): otuqui, arawak, zamuca, chapacura y guaraní (Tomichá, 2002: 243-277). En el contexto de los pueblos de reducción todos estos grupos con sus respectivos nombres fueron reconocidos como «parcialidades» que respondían, cada uno, a un jefe y los jefes de las distintas parcialidades conformaban el cabildo indígena de cada misión (Hoffmann, 1979: 178).

De esta época y del proceso reduccional desarrollado por los jesuitas de la Provincia del Paraguay a través de la fundación de diez pueblos data, por otra parte, la delimitación geográfica de la región. Los contornos de la entonces llamada Provincia de Chiquitos, según informaba el memorial del P. Francisco Burgués en 1705, estaban demarcados por el río Paraguay al este; al oeste por la ciudad de San Lorenzo y la provincia de Santa Cruz de la Sierra; las serranías de los Tapacuras la separaban de las misiones de Mojos dependientes de la Provincia jesuítica del Perú por el norte, y Santa Cruz la Vieja y su serranía marcaban la separación del Chaco al sur (Tomichá, 2008: 89).

En suma, durante el período reduccional la polisemia de chiquitos creció en la misma medida en que su origen interétnico cayó en el olvido. Como ya fue advertido, algo se perdió en el camino de la traducción del guaraní al español que permitió que se generalizara la explicación del nombre a partir del tamaño de sus casas. El sentido cristiano del pudor y el interés por afirmar la condición humana de los indios reducidos también estuvieron presentes en las reinterpretaciones y resignificaciones que sufrió el nombre en esta época. Un jesuita revelaba en el prólogo de una gramática y vocabulario de la lengua chiquita elaborados por él que «el nombre de chiquitos no les viene de los españoles sino de su propio 
lenguaje» de una «raíz tan poco honesta» que los avergonzó cuando los padres «les abrieron los ojos a la fe»: en lengua chiquita, chiquis significa «huevo» y también «testículo» (Falkinger \& Tomichá, 2012b: 359 y 664). Por eso los misioneros les dieron el nombre de $m^{\prime}$ oñeyca «que quiere decir los hombres» (Falkinger \& Tomichá, 2012b: 4. Subrayado en el original), con el que se designaba toda la nación. En efecto, en el vocabulario redactado por este jesuita, «hombre» aparece como ñoñeys (Falkinger \& Tomichá, 2012b: 356) y «humanidad», m’oñeyqui (Falkinger \& Tomichá, 2012b: 359). La explicación esbozada por el misionero y el etnónimo de reemplazo elegido, pues, despiertan la sospecha de que fueron los propios jesuitas y no los indígenas los que decidieron cambiar el nombre. Cabría preguntarse además si los chiquitos se llamaban a sí mismos con ese nombre, que sabemos de origen guaraní-español. El mismo jesuita aclaraba que:

con el nombre de $m^{\prime}$ oñeyca se entiende toda su nación en general y las particulares tribus se distinguen con otros particulares nombres que los diferencia unos de otros (Falkinger \& Tomichá, 2012a: 8. Subrayado en el original).

El registro etnonímico del período jesuita no se agota con la generalización de un nombre para todos los indígenas de la región, sino que se compone de dos códigos: el de la uniformidad y el de la multiplicidad. Así parece indicarlo la proliferación de nombres del censo de Chiquitos por parcialidades realizado en 1745, que seguía reflejando la diversidad de grupos reducidos en las misiones: piñocas, purasis, paicones, quiviquicas, baures, guapas, guarayos, boococas, tubasis, puizocas, yurucarés, zibacas, quimomecas, quitemas, napecas, paunacas, cusicas, tapacuras, taus, tanipicas, etc. (Matienzo et al., 2011: 328-329). Lo mismo puede decirse del registro realizado por el P. Sánchez Labrador en el viaje que por fin logró comunicar la provincia jesuítica del Paraguay con la de Chiquitos (Sánchez Labrador, 1910 [1770]: 82-88). Si la persistencia de los nombres de las parcialidades se debe a que efectivamente seguían teniendo existencia real en el mapa étnico de las misiones, la disponibilidad de documentos en los que aparece registrada es mérito de la atención y del interés que los padres de la Compañía de Jesús le prestaron al asunto; de hecho, el humanismo jesuita es sin duda un gran capítulo de la etnografía y de la etnohistoria americanas. El contraste con la información disponible al respecto para el período posjesuítico es desolador.

Con el advenimiento del absolutismo ilustrado y de la centralización administrativa de las reformas borbónicas se perdió el interés por el registro exhaustivo de los nombres y por la composición de las parcialidades. En el censo de 1768 se las reconoció y registró, pero se debió más a la inercia e imitación del sistema jesuítico que a un verdadero interés por mantener actualizada la información sobre la composición étnica de las doctrinas (ABNB MyCh GRM 24-VI). A los efectos de una mayor eficacia administrativa poco importaba a qué grupo pertenecían. Entonces los indígenas a los que nos venimos refiriendo eran simplemente los que habitaban los pueblos de las misiones, una nación asimilada al territorio de la provincia de Chiquitos, espacio de fijación de la residencia y de transformación de sus habitantes en sujetos políticos y productivos. Si es claro que esta imagen 
corresponde casi con exactitud con el programa y con los objetivos que guiaron a los jesuitas, es en la época posterior a su expulsión cuando su concreción resulta evidente. Producto de una simplificación binaria abrumadora, el panorama étnico que permite bosquejar la evidencia del siglo XVIII borbónico es el que opone «indios», «neófitos» e «infelices» reducidos en los pueblos de misión a «bárbaros»e «infieles» «chiriguanos, potoreras, ymonos, tunachos, guaycurus, guanas, payaguas y sirionós» (AGN Borrador de respuesta..., Carta de Melchor Rodríguez..., Carta de Barthelemí Berdugo...), de manera que el nombre étnico parece haber pasado a ser un atributo exclusivo del indio que horadaba las fronteras de la provincia asaltando los pueblos, robando ganado y objetos de metal y asaltando los caminos o que simplemente desconocía la «vida en policía» de la reducción.

En lo que respecta a las relaciones entre los grupos indígenas de la región, dos cosas resultan evidentes. La primera es que, dos siglos después de los primeros contactos de los españoles con los chiquitos, los papeles entre estos y los guaraníes se habían invertido: los bravos, temibles y escurridizos eran ahora chiriguanos, guarayos y sirionós, mientras que los chiquitos pasaron a ser, desde la época de las reducciones, los indios amigos y colaboradores. Provistos de los tradicionales arcos y flechas que supieron hacerlos temibles ante los ojos de los conquistadores españoles, pasaron a formar la fuerza de choque en expediciones ofensivas contra los chiriguanos (AGN Carta de Alonso...). Por otra parte, si en el Chaco los chiriguanos desde el oeste y los guaycurúes desde el este oficiaban de mediadores entre los blancos y los salvajes que habitaban el corazón de la región, unos grados de latitud más al norte funcionaban justo al revés: rodeaban de barbarie una provincia poblada por indios reducidos a la vida civilizada. En la época colonial chiriguanos y guaycurúes eran el eslabón conocido por los españoles que los conectaba de manera indirecta, fragmentaria y hasta imaginaria con un conjunto encadenado de grupos que se perdía en el corazón del Chaco, área inexpugnable e indescifrable para españoles y criollos (Richard, 2011). Más al norte, chiriguanos y guaycurúes desconectaban Chiquitos de las provincias coloniales de Charcas y Paraguay, entorpecían las comunicaciones y obligaban a destacar fuerzas militares para contenerlos; en suma, eran un cerco que acentuaba la condición de zona de frontera.

En la era borbónica, el hecho de colindar con el reino de Portugal en el tenso marco de la firma y concreción de los Tratados de Madrid y San Idelfonso era prácticamente el único motivo de interés del gobierno virreinal por la provincia de Chiquitos. El establecimiento de villas portuguesas como Vila Bella, Cuiabá y Casalvasco en las proximidades de las orillas orientales de los ríos Guaporé y Paraguay puso a la región en una nueva ebullición10. El alerta de las autoridades españolas y portuguesas no revirtió la porosidad de la frontera, donde el tránsito

10 Sobre la frontera luso-española en el siglo XVIII véase, desde una perspectiva etnohistórica y brasilera, Meireles, 1989; un recorrido de más larga duración en clave geopolítica, Sotomayor 2013. 
de personas, bienes y ganado se había intensificado luego de la expulsión de los jesuitas; la desidia y las desinteligencias de los curas, administradores, gobernadores y virreyes españoles en relación con las misiones provocaron intensas migraciones «de los indios de España», de los «huidos de Castilla» a la capitanía de Mato Grosso, donde eran conocidos como «indios castellanos» (Amado \& Caselli Anzai, 2006: $45,123,201) 11$. Así, la frontera con Portugal sumaba un nuevo denominador al estrato etnonímico borbónico para los indígenas de Chiquitos, calificativo que abarcaba a los indios de la provincia de Mojos, también perteneciente a la corona española. La guerra de independencia hizo lo propio: en su huida en busca de protección al reino de Brasil en 1824, el gobernador realista Sebastián Ramos llevó consigo trescientas familias de indios del pueblo de Santa Ana a Casalvasco donde eran rigurosamente vigiladas para que no abandonaran la villa (d'Orbigny, 2002: 1279, 1337)12.

\section{EL SIGLO XIX Y EL ACIAGO DESTINO DE LOS CHIQUITANOS}

La agudeza de las indagaciones del naturalista francés sacaron a los indígenas de Chiquitos de la apatía homogeneizadora de la era borbónica. La imagen de la región que transmite su relato de viaje revela una continuidad formal con la época jesuita aunque desplegada en el nuevo régimen de los administradores seculares y gobernadores militares y trastocada por la guerra de independencia. En el registro pormenorizado que levantó en su recorrido de un año y medio por las misiones reaparecen, aunque mermados, los nombres de las naciones y tribus que las habitaban. La diversidad de grupos que encontró en el interior del gran conglomerado humano de la región de Chiquitos no inhibía una mirada sombría sobre el destino indígena de la región. No sin pesar, d'Orbigny vio logrado el cometido de chiquitanización lingüística de los jesuitas en cada intento frustrado de registrar vocabularios de lenguas no chiquitas. En la misión de Concepción encontró que, además del chiquito, los quitemocas y los paiconecas hablaban su propia lengua en el ámbito familiar, pero las consideró condenadas a desaparecer antes de medio siglo; en Santa Ana solo un viejo saraveca hablaba bien su idioma, mientras que los covarecas y curuminacas habían olvidado su lengua materna. En San Rafael los curucanecas y cobarecas se habían fundido tan bien con los chiquitos que ya no recordaban su idioma primitivo; su intención de redactar un vocabulario morotoca en San Juan se malogró por el olvido de los jóvenes de ese grupo. En Santiago los guarañocas conservaban su idioma porque eran mayoría,

11 Con estas migraciones de indígenas desde las misiones hacia territorio portugués comienza el asentamiento en la capitanía del Mato Grosso que dio origen a los chiquitanos del Mato Grosso, quienes siempre fueron considerados indios bolivianos y reconocidos como grupo indígena por la Funai (Fundação Nacional do Indio, Brasil) recién en 1988. Actualmente son alrededor de 2400 personas asentadas en 32 comunidades a lo largo de la frontera boliviano-brasilera. Al respecto véase Meireles, 1989; Bortoletto Silva, 2007; Fernandes Silva, 2008.

12 Los números varían en El Hombre Americano, donde d'Orbigny alude a trescientos indígenas de Chiquitos entre quienes identificó cien saravecas y cincuenta curuminacas (1944 [1839], 320 y 323). 
pero los tapiis habían olvidado el suyo. Sin embargo, la información recogida por Castelnau quince años después matiza y llama a tomar con precaución el panorama caracterizado por d'Orbigny. El viajero francés que recorrió la región a mediados de 1845 encontró que en Concepción se hablaban siete lenguas diferentes: tapacuraca, napeca, paunaca, paiconeca, quitemoca, jurucariquia y moncoca. En Santa Ana la lengua común era la saraveca; en Santiago, confirmaba que se hablaba el idioma de los guaraniocas y en San Juan el de los morotocas se usaba tanto como la lengua chiquita general, entonces llamada moncoca (Castelnau, 1853: 223). En cualquier caso, no es el predominio de la lengua chiquita lo que está en discusión - a cuya posible existencia prejesuítica e incluso prehispánica ya se hizo referencia-, sino la pervivencia o no de lenguas pertenecientes a otras familias.

En la omnipresencia y en la inexorable preponderancia regional de lo chiquito en la región se basó la invención de un nuevo nombre para el conjunto indígena que la habitaba que, con leves modificaciones léxicas - pero con profundos cambios de contenido- , se mantiene hasta hoy: la rama chiquiteana (d'Orbigny, 1944 [1839]: 34). En su origen fue una categoría taxonómica que distinguía a los chiquiteanos de otras ramas de la raza pampeana de indígenas que habitaban las tierras bajas de América del Sur. El nombre derivaba de chiquitos, porque estos «conforman seis séptimos de la población del país», mientras que el séptimo restante lo componían las naciones samucu, payconeca, saraveca, otuque, curuminaca, curaré, covareca, tapii13 y curucaneca. Mientras que d'Orbigny discriminaba naciones a partir de un criterio lingüístico, la delimitación de las ramas respondía a otro geográfico, que incidía en sus características morales:

llamamos rama a un grupo más o menos numeroso de naciones distintas que presentan $[\ldots]$ características físicas o morales que determinan estas divisiones [de la raza en ramas] casi siempre en relación con la geografía local (d'Orbigny, 1944: 30-31).

De manera que los chiquiteanos eran «todos los indígenas americanos de la provincia de Chiquitos». Si la época jesuítica fue el momento de transformación de un etnónimo en topónimo, la era naturalista cierra el ciclo acuñando un etnónimo con aspecto de gentilicio y asociando el nombre del pueblo indígena con el territorio que habitaba. Es la inversión de la relación entre el indígena y el lugar, transformada por el peso del proceso histórico de fijación de los indígenas al territorio y de indios chiquitos a provincia de Chiquitos, a indios chiquiteanos. En efecto, entre las características que resumían la peculiaridad de la rama chiquiteana estaban ciertos rasgos fenotípicos, «un carácter alegre, bueno y sumiso», el desarrollo de actividades agrícolas y «la facilidad con que se adaptó al cristianismo y se sometió al régimen de las misiones» (d'Orbigny, 1944: 304). La sumisión de los chiquiteanos resultaba más evidente en la comparación con los «salvajes guarayos». Una vez más los chiquitos aparecían reflejados en el espejo invertido guaraní, actualizando en cada situación el contraste estructural hombre libre-esclavo en el que estos últimos depositaban la definición de su identidad. El aspecto de los guarayos de

${ }_{13}$ No obstante la similitud de este nombre con el de los tapii miri quinientistas, se trata de tapios o sapios (zamucos). 
la reducción de Ascención despertó el respeto de d'Orbigny porque mostraban una imagen de libertad notable en comparación con los indios de las misiones. El guarayo «se enfada cuando lo tratan de indio, sosteniendo con altanería: "sólo los chiquitos son indios, pues son esclavos; yo soy libre y no indio: soy guarayo"» (d'Orbigny, 2002: 1345. Subrayado en el original). Pero también se hacían eco de la deshonestidad en la que habían caído los chiquitanos luego de la expulsión de los jesuitas, producto del régimen corrupto de los curas doctrineros y de los administradores. Los guarayos repugnaban a los chiquitos que, escapando de la severidad de las misiones, se iban a vivir con ellos «por las exacciones que cometen y por la depravación de sus costumbres» (d'Orbigny, 2002: 1352). El propio d'Orbigny no había escatimado en quejas sobre su deshonestidad, la relajación de la disciplina jesuítica y la promiscuidad de las mujeres de Chiquitos que se oponían al escrúpulo de los guarayos, su horror por el robo y el adulterio y la conducta intachable de sus mujeres (d'Orbigny, 2002: 1348).

El nuevo nombre chiquiteanos prendió pronto entre los viajeros, expedicionarios y misioneros que sucedieron a d'Orbigny. En verdad, más que el nombre, el sentido territorial y gentilicio que encerraba: eran los chiquiteños del informe de Maurice Bach, con aptitudes para aprender oficios y para sobrellevar «con constancia el hambre, los dolores, las fatigas y adversidades de la vida» aunque abandonados y flojos para el trabajo (Bach, 1929 [1842]: 42) o los chiquiteños que en 1850 seguían pagando el tributo del régimen reduccional con cera, sal y algodón, a la vez que participaban en el mercado de Oliden vendiendo sombreros de paja y hortalizas, para complementar sus ingresos (Herndon \& Gibbon, 1854: 164-165, 168). Por otra parte, en unos versos en guaraní que el Padre José Cors recogió entre los guarayos, los indígenas de Chiquitos aparecen, traducción del franciscano mediante, bajo dos nuevas denominaciones: guayana y chiquitano:

Mbuyui chimini yemoyere remi, / Co che ayu nde pepi-pe, Guayana; / Nde pepi-pe, Guayana, que traducidos literalmente al castellano dicen: Cual pequeña golondrina revoloteando, / Así vengo yo á tu banquete, Chiquitano; / A tu banquete, Chiquitano (P. José Cors citado en Cardús, 1886: 73).

Aunque en esta ocasión es traducido como sinónimo de chiquitano, guayana es el nombre que los guaraníhablantes aplicaban a los no guaraníes y que transpusieron a sus vecinos chiquitanos (Susnik, 1968: 42; Combès, 2015 en prensa) de manera que su significado podría entenderse en términos de «una discriminación racial y cultural en oposición a la etnocéntrica consciencia de la 'avá-idad'», es decir, de ser libre en oposición con el ser esclavo o tapii (Susnik, 1979 citada en Combès, 2015 en prensa). En resumidas cuentas, el juego de oposiciones guaraní-chiquito seguía en pie y su sentido intacto.

Para las últimas décadas del siglo XIX chiquitano se había generalizado, pero el contenido del nombre había vuelto a cambiar. Los pueblos de las antiguas misiones en los que se los solía situar se encontraban en decadencia por la huída o migración de sus habitantes. «Para evitar las gravosas molestias de los blancos» los paunacas junto con los napecas se habían escapado del pueblo de 
Concepción (Cardús, 1886: 296; Ducci, 1895: 72; Nordenskiöld, 2003 [1922]: 79-80); la parcialidad de los penoquiquias se fugó del pueblo de San José; se creía que se habían dirigido al sur, que vivían entre las salinas de San José y el Isoso, que asaltaban estancias para abastecerse de herramientas de metal y que se los conocía como empelotos 14 (Cardús, 1886: 272-273; Balzán, 2008: 252). Otros habían despoblado las reducciones y vivían empadronados en estancias como la de Dolores, un «rancho con plaza en el centro» a $38 \mathrm{~km}$ al oeste de San José por el camino hacia Corumbá, o la cabaña San Pedro más adelante sobre el mismo camino (Balzán, 2008: 253). En el norte de la provincia los chiquitanos trabajaban pasando cargas y animales y manejando las canoas que cruzaban el río San Miguel a la altura del puerto San Julián, unos kilómetros al sudoeste de la ex misión de San Xavier. Cerca de San Julián estaba el pueblo de San Ramón, «de indios chiquitanos y de blancos, por supuesto, patrones y amos de indios» (Ducci, 1895: 69-70). Un poco más al norte, el pueblo de Santa Rosa ofrecía otro ejemplo de lo mismo: «un pueblo de blancos e indios chiquitanos, es decir de señores y siervos» (Ducci, 1895: 70) donde desde la década de 1870 los patrones a los que estaban sujetos los distribuían a cambio de dinero entre explotadores mineros para emplearlos en lavaderos de oro (Chacon, 1877: 11). La explotación del caucho en el Beni y el Guaporé creó, por su parte, una corriente migratoria de indios chiquitanos hacia el norte (Vaudry, 1908: 231). Se los encontraba en Pezoé y en Huanchaca, en el Alto Paraguá, al norte de la provincia de Velasco del departamento de Santa Cruz (Chervin, 1908: 69, 70, 73), pero también en lugares mucho más distantes como La Loma, barraca ubicada sobre el río Ibary, afluente del Mamoré, a corta distancia de Trinidad, en el departamento del Beni (Nordenskiöld, 2001 [1924]: 235). Igualmente se les veía en la barraca Pimenteira, ubicada sobre la costa norte del río Guaporé, por debajo de los 14 o de latitud sur, cuyos trabajadores eran exclusivamente indios chiquitanos (Nordenskiöld, 2001: 281) y también más al norte, en las barracas Cuellar (Nordenskiöld, 2003: 194) y Curicha, esta última próxima a la costa del río Guaporé por debajo de los 13oㅡ, donde vivían junto con baures e itonama (Nordenskiöld, 2003: 134). Entonces, mientras los indígenas de las misiones que se «remontaban» y retornaban a la vida «salvaje» recuperaban los

${ }_{14}$ Según Giannecchini, los empelotos eran llamados así por su escasez de ropa. El nombre sería la traducción de itirumbae, «sin tiru», es decir, sin el vestido tradicional de los hombres chiriguanos (Gianecchini, 1916: 198-199), que aparentemente era un término tan genérico como tapii o tapiete usado por los guaraníhablantes para designar a diferentes grupos no guaraníes. Entre ellos podrían contarse grupos zamucohablantes y los tapiete próximos al Isoso en el Chaco (Combès, 2004). Los empelotos pudieron haber sido también los «fugitivos escondidos» chané que huyeron de los chiriguanos del Parapití y se instalaron en el Chaco (Combès, 2008b). Cardús asoció a los penoquiquias devenidos empelotos con los zamucos (Cardús, 1886: 273). Pero el nombre penoquiquia —o penoquías para Balzán (2008 [1885-1893]: 327)—, sin pretender que designa a los «descendientes» de los peñoqui reducidos por los jesuitas en el siglo XVIII, guarda una estrecha similitud con el de aquella parcialidad que, por otra parte, dio nombre a uno de los dialectos de la lengua chiquita. En cualquier caso, la atribución del nombre de empelotos parece estar más asociada con su condición de «remontados» y «salvajes» que con alguna adscripción étnica definida a partir de criterios lingüísticos. Por otra parte, es un ejemplo más de traducción al castellano de categorías usadas por los guaraníes para denotar el carácter ajeno a su grupo de los que eran así denominados. 
nombres de sus parcialidades — paunacas, napecas, penoquiquias - o cobraban nuevas denominaciones —empelotos-, los que abandonaban los pueblos para trabajar en estancias, en la explotación aurífera, en la carga y transporte o en las barracas caucheras conservaban el nombre de chiquitanos, incluso cuando se trasladaban a grandes distancias. «Chiquitano» se había convertido en sinónimo de trabajador forzado, sujeto a sus patrones y empujado por estos a desempeñarse en actividades productivas y extractivas.

Los religiosos y etnógrafos que visitaron la región coincidieron en el diagnóstico: «son esclavos de hecho pues no tienen la libertad necesaria para disponer sobre sí mismos» (Ducci, 1895: 72), víctimas de «los abusos que cometen con ellos los patrones y enganchadores de gente» (Burela, 1912: 397), «desmoralizados por la bebida» (Minchin, 1881: 411), vivían hacinados bajo el mismo techo en las barracas, donde las mujeres se prestaban a la promiscuidad y «celebran orgías de borrachera y baile» en las que surgían riñas entre los hombres con mucha facilidad (Nordenskiöld, 2003: 134; 2001: 235-281-282). Los pronósticos no podían ser menos que funestos: en las barracas se propagaban velozmente las enfermedades venéreas y la mortalidad de los niños era muy alta (Nordenskiöld, 2003: 135); los chiquitanos iban a desaparecer por los abusos de los patrones y enganchadores, como había sucedido con los mojeños; las migraciones a los gomales dejaban a los pueblos en estado de miseria y ruina y pronto no se encontrarían más indígenas para realizar el trabajo en las haciendas y estancias (Cardús, 1886: 157, 299; Burela, 1912: 397)15.

\section{RETORNO Y COMUNALIZACIÓN}

Pero el destino augurado para los chiquitanos se torció a partir de la segunda década del siglo pasado. En 1913, en su tercer viaje por Sudamérica, Erland Nordenskiöld advertía que, por la crisis del caucho, quienes habían migrado para trabajar en esa actividad, regresaban a sus lugares de origen (Nordenskiöld, 2001: 287). Los habitantes de la comunidad Quince de Agosto, a $62 \mathrm{~km}$ al oeste de San Ignacio de Velasco (capital de la provincia de Velasco del departamento de Santa Cruz) relatan que, luego de abandonar los gomales de Huanchaca, en 1920 volvieron a vivir a la propiedad San Martín, donde estaban empadronados (AAVV, 2006: 274). Los rumores de venta de la propiedad y los malos tratos que recibían por parte de su patrón impulsaron a los chiquitanos que trabajaban allí a tomar la decisión de trasladarse a otras tierras, lo que concretaron entre 1975 y 1976 (AAVV, 2006: 283-287). En San Antoñito, pueblo situado a 18 km al oeste de San Ignacio, cuentan que los fundadores de la comunidad salieron de los gomales en

15 Estas denuncias de las condiciones de trabajo de mojeños y chiquitanos en las barracas gomeras, así como los descargos contra los enganches y el régimen de empatronamiento forman parte de informes y alegatos en defensa de las misiones de guarayos, muy cuestionadas por empresarios y partidarios de la liberación de mano de obra a favor de las empresas extractivas que se desarrollaban en la región a finales del siglo XIX. Es en este marco en que debe ser leída la caracterización que ofrecen sobre la situación de los indígenas. 
1921 y se asentaron en San Pedrito, luego se mudaron a San Miguelito y Totaicito hasta su reunión definitiva en 1963 en las tierras que ocupan actualmente (AAVV, 2006: 181). Entre fines de la década de 1920 y principios de la de 1930 otras familias comenzaron a salir de las estancias y haciendas para formar comunidades de manera independiente en tierras que trabajarían con fines de autosubsistencia. Es el caso de la comunidad San Pablo de Guamopocito (a 27 kilómetros al sur de San Ignacio de Velasco), cuyos fundadores salieron de la propiedad Los Pizotos en 1928 y el de San Rafaelito de Suponema (a 10 kilómetros al oeste de Santa Ana) que estaban empadronados en la finca San Josema y se fueron en 1931 (AAVV, 2006: 113, 147). Procesos similares tuvieron lugar en el sur de la Chiquitania. Las familias que se encontraban empadronadas en las estancias disponían de parcelas destinadas a cultivos de autosubsistencia con los que complementaban el pago que recibían por parte de sus patrones. El reclutamiento para la guerra del Chaco dejó despobladas muchas de esas parcelas, que fueron ocupadas nuevamente cuando terminó el conflicto, pero ya de manera libre y autónoma por los ex combatientes que regresaron a la región (Thiele \& Nostas, 1994: 19). Con estos procesos de asentamiento en comunidades los chiquitanos intentaban librarse de los abusos de sus patrones o asentarse en lugares aislados donde los estancieros blancos y mestizos no pudieran invadir sus tierras (AAVV, 2006: 236, 268-269; Riester, 1976: 138; Balza Alarcón, 2001: 199). Por otra parte, durante la década de 1940, la demanda de mano de obra para la construcción de la vía del ferrocarril atrajo a muchas familias chiquitanas que se asentaron en comunidades ya existentes o crearon nuevos ranchos alrededor de la línea que une Santa Cruz con Puerto Suárez (Thiele \& Nostas, 1994: 20-21; Balza Alarcón, 2001: 200-201).

Según el registro etnográfico de Riester en Lomerío (destino de las familias expulsadas de los alrededores de la ex reducción de Concepción, provincia Ñuflo de Chaves), las nuevas comunidades se formaron por parcialidades: en Rancho Tacuaral vivían juntos los napeca y los quitemoca, mientras que en Santa Rita y en Retiro se asentaron los paunaca (Riester, 1986: 32). La tentación de pensar que se trata del retorno de los fugitivos que se remontaron de Concepción a fines del siglo XIX a través de sus descendientes es tan inevitable como difícil de comprobar. Pero si algo se puede sacar en limpio de la aparición recurrente de estos nombres es que parecen estar lejos de responder a una mera formalidad. Más aún si tomamos en cuenta que en esas comunidades se hablaba, aparte del moncoca, lengua chiquita común, el paunaca y el quitemoca (Riester, 1986: 32). A lo que se agrega, por otra parte, un vocabulario saraveca levantado a mediados del siglo XX por Max Fuss con los datos que le aportaron ciertos informantes de Santa Ana de Velasco (Riester, 1986: 19).

\section{CONSIDERACIONES FINALES}

De alcance incierto durante los primeros contactos con los conquistadores del siglo XVI a causa de su condición de nombre puesto por terceros, chiquitos encierra en su origen una relación entre grupos indígenas transformada por la 
mediación de los conquistadores españoles. En esas condiciones, parece inevitable que el contorno del grupo o conjunto de grupos a los que el nombre aludía sea difuso. Solo cobró nitidez cuando en el siglo XVIII los jesuitas lo llenaron con un nuevo contenido de acuerdo con sus parámetros sociales, políticos, culturales y geográficos. Chiquitos pasó a ser el nombre de una nación indígena, el nombre de una lengua y el nombre de un lugar; en suma, una categoría sobre la que se erigió el mundo social de las misiones jesuíticas de la región. En esta situación colonial tuvo lugar un proceso análogo que inspiró a Pacheco de Oliveira (1998) para acuñar el concepto de territorialización: una reorganización que creó una nueva unidad sociocultural, la constitución de mecanismos políticos especializados y la redefinición del control de los indígenas sobre los recursos ambientales de la región. Entonces, los indígenas reducidos a la vida en policía, disciplinados bajo normas culturales inspiradas en la religión católica y entrenados para el trabajo productivo se convirtieron en m'oñeyca, «los hombres». Si los significados de los nombres requieren ser interpretados en el contexto interétnico en el que son usados, m'oñeyca, «los hombres» de Chiquitos, eran «los indios civilizados» por contraposición con los bárbaros guaycurúes y chiriguanos.

Sobre la base de esta asociación con el territorio y con pautas de vida cristiana, productiva y política se forjó la categoría con la que se los reconoce hasta el presente: chiquiteanos, chiquiteños, chiquitanos. Estos chiquiteanos de las misiones, definidos por su relación íntima con el territorio en el que habían sido fijados desde el proceso reduccional, pasaron a formar parte del patrimonio privado de estancieros y hacendados que ocuparon las tierras de la Chiquitania desde mediados del siglo XIX (Riester, 1976; Radding, 2005: 136-145; Balza Alarcón, 2001: 175-177). El liberalismo decimonónico transformó la atadura al territorio en sujeción al patrón; no resulta extraño, entonces, que aún cuando estos indígenas fueran dislocados de sus lugares de origen por la fiebre del oro y por el boom del caucho, conservaran el nombre chiquitano. El nombre llevaba la marca del empatronamiento y probablemente la garantía del retorno, como efectivamente sucedió con muchos de ellos. Estas condiciones sumadas a la crisis del caucho explican el regreso a las estancias de los chiquitanos que estaban en los gomales; lo que todavía queda por saber son las causas que los impulsaron a abandonar las estancias y a fundar comunidades autónomas y con fines de autosubsistencia desde finales de la década de 1920. La intención de huir de los malos tratos de sus patrones no resulta ser un motivo suficiente si tenemos en cuenta que llevaban décadas padeciéndolos. La adquisición de cierta conciencia nacional, de clase y/o étnica, a partir de la experiencia de la guerra del Chaco señalada por algunos autores (Thiele \& Nostas 1994: 19; Balza Alarcón, 2001: 197), espera la profundización de investigaciones que la confirmen o la refuten.

Mientras que el indígena empatronado que regresaba era chiquitano, el que huía al monte era penoquiquia, napeca, quitemoca, paunaca o paiconeca. La omnipresencia de estos nombres a lo largo de la historia indígena de la región no puede ser soslayada o interpretada como un simple reflejo o pervivencia de la división en parcialidades de las reducciones jesuíticas. La ecuación parece ser la inversa: si los pueblos de reducción y sus instituciones políticas fueron 
organizados teniendo en cuenta estas parcialidades, fue porque los grupos en cuestión estructuraban el mapa étnico de la región desde antes. La etnificación (Boccara, 2005 sensu) y la territorialización de la época jesuita y la parquedad de los documentos oficiales al respecto tendieron a forjar la idea de que el objetivo de cristianización y estandarización lingüística fue ampliamente cumplido en la Chiquitania y que «lo chiquitano», entendido como sinónimo de cultura misional, reemplazó a otras identidades étnicas que inicialmente formaron parte de las reducciones (Tomichá, 2002). Sin embargo, las divisiones que conformaban las parcialidades de los pueblos siguieron gravitando en la vida cotidiana de los indígenas no solo en el interior de ellos sino también -y sobre todo- fuera o, para ser más elocuentes, a la hora de huir de ellos. La recurrente aparición en escena de grupos de personas que se identificaban con nombres sepultados bajo la hipótesis de la homogeneización trastoca esa imagen tradicional de la cultura chiquitana como sinónimo de cultura misional e invita a pensar en otras interpretaciones. A tal efecto, la aproximación breve e incipiente presentada en este trabajo requiere ciertamente ser abordada con mucho más profundidad. Aún así, es posible arriesgar que más que un reemplazo de «lo no chiquito» por «lo chiquitano», coexistieron dos clases de identidad étnica en esferas de interacción16 distintas. Una, asignada por los agentes colonizadores, de alcance general, de visibilidad y transmisión pública y de carácter formal e institucional, que fue superpuesta y coexistió con otras. Estas últimas, de alcance más acotado, de uso y transmisión domésticos, acaso ejemplos de identidades latentes ${ }^{17}$ y tal vez por ello escasamente perceptibles en el registro oficial pero más visibles en circunstancias excepcionales. Es probable que la conformación de comunidades indígenas en la Chiquitania a lo largo del siglo XX, por medio de la ocupación de tierras por unidades domésticas y parcialidades, haya sido llevada adelante por grupos identitarios más acotados, tal vez estructurados en torno a relaciones de parentesco (Riester, 1986; Balza Alarcón, 2001: 199).

Por último, un párrafo dedicado al expediente guaraní-chiquito, que fue sumando fojas a lo largo de este recorrido para llegar a la conclusión de que no hay nada que se haya mantenido más constante a lo largo de los cuatro siglos que separan las crónicas de los conquistadores quinientistas del registro de los franciscanos decimonónicos que el lugar que ocupan los indígenas de Chiquitos en las

16 Como las definió Harald Eidheim (en Barth, 1976: 70) para distinguir el ámbito de la «vida pública» del de la «vida secreta» de los lapones, grupo indígena que, para evitar la estigmatización de la sociedad noruega, se reservaba para la esfera privada la manifestación de los rasgos asociados con su identidad, siendo el uso de la lengua el principal de ellos.

17 En términos de Cardoso de Oliveira (2003: 124), a propósito del concepto de surrendered identity de Erikson, una identidad latente es una identidad que por amenazada es renunciada aunque no por completo y que puede ser invocada en cualquier momento. Sobre la estigmatización de identidades y nombres en Chiquitos, Riester señaló la disolución del grupo de los paiconecas (o su absorción entre los paunacas, ambos grupos hablantes de lenguas clasificadas dentro de la familia lingüística arawak) entre las comunidades de Lomerío en el siglo XX, que pudo haberse debido a que hayan renunciado a él, por el sentido despectivo que adquirió el apócope de su nombre, «paico», usado por los blancos para referirse a los chiquitanos como sinónimo de lento y sonso (Riester, 1986: 104). 
definiciones étnicas guaraníes. Tapuy miri o guayana, chiquito como sinónimo de indio, e indio como equivalente de esclavo: para los guaraníes los chiquitos fueron, en definitiva, uno de los tantos grupos en contraposición con los cuales reafirmaron siempre que pudieron su condición de hombres libres. Y esto ocurrió independientemente de la circunstancia en la que los guaraníes se encontraran en relación con los blancos. Podían ser los colaboradores de los conquistadores españoles del siglo XVI y los chiquitos sus más feroces y temidos enemigos; podían vivir en el bosque habiendo desertado recientemente de las misiones y los chiquitos vivir reducidos en los pueblos desde larga data; podían conformar ellos mismos la población de misiones franciscanas y refugiarse así de los enganches para ir a trabajar a los gomales y los chiquitos haberse perdido en las fiestas y borracheras de las barracas. No importaban las circunstancias: los chiquitos eran siempre mirados desde el lugar de superioridad que les otorgaba a los guaraníes y a los guarayos el hecho de saberse libres, «hombres sin dueño».

En el recorrido histórico por la etnonimia chiquitana y por las relaciones interétnicas en las que fue forjada, empleada y circulada, resulta evidente que la situación no permaneció inmóvil desde la llegada de los primeros conquistadores — ni desde la de los jesuitas — hasta la actualidad, y que los procesos sociohistóricos subsiguientes tuvieron tanta repercusión sobre su vida, sus manifestaciones culturales y las definiciones de su identidad étnica, que aún cuando se asemeje en la forma, el contenido del chiquiteanos de d'Orbigny no es el mismo que el de los actuales chiquitanos. Para la definición diacrónica de la identidad chiquitana, y pese a lo que se supone habitualmente, la historia posjesuítica fue tan decisiva, fundante e instituyente como la jesuítica. Es la mirada de largo aliento que proyecta a los chiquiteanos, los chiquitos, los tapuy miri y los tovacicoçi y tantos otros grupos y nombres de los que falta conocer, la que nos permite entender de forma profunda y cabal el significado actual de ser chiquitano.

\section{Referencias citadas}

Archivos

ABNB Archivo y Biblioteca Nacionales de Bolivia

MyCh Mojos y Chiquitos

AGN: Archivo General de la Nación, Argentina

Borrador de respuesta por parte del virrey del Río de la Plata a carta del gobernador de Chiquitos sobre lo indefensa que se encuentra la provincia en caso de invasión. 25 de enero de 1800. AGN Sala IX Legajo 20-7-6 Gobierno de Chiquitos.

Carta de Alonso Berdugo a Juan Manuel de Amat del 6 de julio de 1765. Sala IX Legajo 7-1-6 Gobierno de Santa Cruz.

Carta de Barthelemi Berdugo (sic) al virrey José de Vertiz del 26 de abril de 1780. AGN Sala IX Legajo 20-7-6 Gobierno de Chiquitos.

Carta de Melchor Rodríguez al virrey Nicolás Arredondo del 25 de marzo de 1792. AGN Sala IX Legajo 20-7-6 Gobierno de Chiquitos. 
Tapuy miri, chiquitos, chiquitanos. Historia de un nombre en perspectiva interétnica

AAVV, 2006 - La voz de los chiquitanos. Historias de comunidades de la provincia de Velasco. Guapomocito, Suponeca, San Antoñito, Monte Carlo, Quince de agosto, 314 pp.; Santa Cruz: Fondo Editorial Asociación Pro Arte y Cultura (Apac), Fundación Avina.

ADAM, L. \& HENRY, V., 1880 - Arte y vocabulario de la lengua chiquita, 136 pp.; París: Maisonneuve y Cia. Libreros Editores.

AMADO, J. \& CASELLI ANZAI, L. (orgs.), 2006 - Anais de Vila Bela 1734-1789, 319 pp.; Cuiabá: Editora da Universidade Federal de Mato Grosso, Carlini y Caiato Editorial.

BACH, M., 1929 [1842] - Descripción de la nueva provincia de Otuquis en Bolivia, 39 pp.; La Paz: Lit. e Imp. «Unidas».

BALZA ALARCÓN, R., 2001 - Tierra, territorio y territorialidad indígena. Un estudio antropológico sobre la evolución en las formas de ocupación del espacio del pueblo indígena chiquitano de la ex-reducción jesuita de San José, 355 pp.; Santa Cruz de la Sierra: Apoyo Para el Campesino-Indígena del Oriente Boliviano (Apcob), Servicio Holandés de Cooperación al Desarrollo (SNV), Grupo Internacional de Trabajo sobre Asuntos indígenas (Iwigia).

BALZÁN, L., 2008 [1885-1893] - A carretón y canoa. La obra del naturalista Luigi Balzan en Bolivia y Paraguay (1885-1893), 419 pp.; La Paz: Instituto Francés de Estudios Andinos (IFEA), Institut de Recherche pour le Développement (IRD), Embajada de Italia, Plural editores.

BARTH, F. (ed.), 1976 - Los grupos étnicos y sus fronteras, 204 pp.; México: Fondo de Cultura Económica.

BOCCARA, G., 2005 - Mundos nuevos en las fronteras del Nuevo Mundo. Nuevo mundo mundos nuevos, Debates, Puesto en línea el 8 de febrero de 2005, consultado el 18 de julio de 2013. URL: http://nuevomundo.revues.org/426; DOI:10.4000/ nuevomundo, 426 .

BORTOLETTO SILVA, R., 2007 - Os Chiquitano de Mato Grosso: estudo das classificações sociais em um grupo indígena da fronteira Brasil-Bolivia, 226 pp.; São Paulo. Tesis de doctorado.

BURELA, B., 1912 - Contribución al estudio de la etnografía boliviana. Boletín de la Oficina Nacional de Estadística de Bolivia, Año VIII, n.o 81, 82, 83 y 84: 394-410.

CARDOSO de OLIVEIRA, R., 2003 [1971] - Identidade étnica, identificaçao e manipulaçao. Sociedade e cultura, 6: 117-131.

CARDÚS, J., 1886 - Las misiones franciscanas entre los infieles de Bolivia, 430 pp.; Barcelona: Librería de la Inmaculada Concepción.

CASTELNAU, F. de, 1853 - Expédition dans les parties centrales de l'Amérique du Sud de Rio de Janeiro a Lima, et de Lima au Para, 483 pp.; París: P. Bertrand. Troixième Tome.

CHERVIN, A., 1908 - Anthropologie bolivienne. Tome premier. Ethnologie, démographie, photographie métrique, 411 pp.; París: Imprimerie nationale.

CHACÓN, T., 1877 - Empresa de lavaderos auríferos en la provincia boliviana de Chiquitos colindante de Mattogroso, 21 pp.; Buenos Aires: Imprenta de M. Biedma.

COMBÈS, I., 2004 - Tras las huellas de los ñanaigua: de tapi, tapiete y otros salvajes en el Chaco boliviano. Bulletin de I'Institut Français d'Études Andines, 33 (2): 255-269.

COMBÈS, I., 2006 - Coçi: hacia una relectura de la historia del oriente boliviano. In: Definiciones étnicas, organización social y estrategias políticas en el Chaco y la Chiquitania (I. Combès, ed.): 69-79; Santa Cruz de la Sierra: Instituto Francés de Estudios Andinos (IFEA), Editorial El País, Servicio Holandés de Cooperación al Desarrollo (SNV). 
COMBÈS, I., 2008a - Planchas, brazaletes y hachuelas: las rutas prehispánicas del metal andino desde el Guapay hasta el Pantanal. Revista Andina, 47: 53-82.

COMBÈS, I., 2008b - Los fugitivos escondidos: acerca del enigma tapiete. Bulletin de I'Institut Français d'Études Andines, 37 (3): 511-533.

COMBÈS, I., 2010 - Diccionario étnico. Santa Cruz la Vieja y su entorno en el siglo XVI, 406 pp.; Cochabamba: Instituto de Misionología de la Universidad Católica de Bolivia.

COMBÈS, I., 2012 - Susnik y los gorgotoquis. Efervescencia étnica en la Chiquitania (oriente boliviano). Indiana, 29: 201-220.

COMBÈS, I., 2015 - De la una y otra banda del río Paraguay. Historia y etnografía de los itatines (siglos XVI-XVIII). Cochabamba: Itinerarios. En prensa.

COMBÈS, I. \& SAIGNES, T., 1991 - Chiri-guana: nacimiento de una identidad mestiza. In: Chiriguano (J. Riester, ed.): 25-221; Santa Cruz de la Sierra: Apoyo Para el Campesino-Indígena del Oriente Boliviano (Apcob).

DUCCI, Z., 1895 - Diario de la visita a todas las misiones de Bolivia - América meridional practicada por el MRP Sebastián Pifferi Comisario General de los colegios de la misma república, escrito por su secretario y compañero de viaje. Ambos misioneros del Colegio Apostólico de Tarija, 189 pp.; Asís: Tipografía de la Porciúncula.

FALKINGER, S. \& TOMICHÁ, R. (eds.), 2012a - Gramática de los Chiquitos (s. XVIII), 181 pp.; Cochabamba: Instituto Latinoamericano de Misionología, Editorial Itinerarios.

FALKINGER, S. \& TOMICHÁ, R. (eds.), 2012b - Vocabulario de los Chiquitos (s. XVIII), 714 pp.; Cochabamba: Instituto Latinoamericano de Misionología, Editorial Itinerarios.

FERNANDES SILVA, J. A. (org.), 2008 - Estudos sobre os chiquitanos no Brasil e na Bolívia: história, língua, cultura e territorialidades, 316 pp.; Goiânia: Editora UCG.

FERNÁNDEZ, J. P., 1895 [1726] - Relación historial de las misiones de indios Chiquitos que en el Paraguay tienen los padres de la Compañía de Jesús, 2 vols., 607 pp.; Madrid: Librería de Victoriano Suárez.

FERRIÉ, F., 2013 - Renaissance des lecos perdus. Ethnohistoire du piémont d'Apolobamba à Larecaja; Nanterre: Université de Paris Ouest Nanterre la Défense. Thèse de Doctorat en Etnologie

GIANNECCHINI, D., 1916 - Diccionario Chiriguano-Español y Español-Chiriguano, 2 tomos, 256 y 190 pp.; Tarija: Publicación de la Orden Franciscana.

GIANNECCHINI, D., 1996 [1898] - Historia natural, etnografía, geografía, lingüística del Chaco boliviano, 459 pp.; Tarija: Fondo de Inversión Social, Centro Eclesial de Documentación.

HERNDON, L. \& GIBBON, L., 1854 - Exploration of the valley of the Amazon, Part II, 425 pp.; Washington: A.O.P. Nicholson, Public Printer.

HERVÁS y PANDURO, L., 1800 - Catálogo de las lenguas de las naciones conocidas y numeración, división, y clases de éstas según la diversidad de sus idiomas y dialectos, Volumen I. Lengua y naciones americanas, 396 pp.; Madrid: Imprenta de la Administración del Real Arbitrio de Beneficencia.

HOFFMANN, W., 1979 - Las misiones jesuíticas entre los Chiquitanos, 199 pp.; Buenos Aires: Fundación para la Educación, la Ciencia y la Cultura.

INSTITUTO NACIONAL DE ESTADÍSTICA, 2012 - Censo nacional de Población y Vivienda del Estado Plurinacional de Bolivia, 31 pp.

JULIEN, C., 2006 - La descripción de la población del oriente boliviano en el siglo XVI. In: Definiciones étnicas, organización social y estrategias políticas en el Chaco y la 
Tapuy miri, chiquitos, chiquitanos. Historia de un nombre en perspectiva interétnica

Chiquitania (I. Combès, ed.): 49-67; Santa Cruz: Instituto Francés de Estudios Andinos (IFEA), Editorial El País, Servicio Holandés de Cooperación al Desarrollo (SNV).

MATIENZO, J., TOMICHÁ, R., COMBÈS, I. \& PAGE, C., 2011 - Chiquitos en las Anuas de la Compañía de Jesús (1691-1767), 458 pp.; Cochabamba: Instituto Latinoamericano de Misionología, Editorial Verbo Divino.

MEIRELES, D. M., 1989 - Guardiães da fronteira. Rio Guaporé, século XVIII, 213 pp.; Río de Janeiro: Editora Vozes.

MEMORIA Y RESOLUCIÓN ..., 2008 [1560] - Memoria y resolución de los casos y cosas sucedidas en la tierra de la gobernación de Juan de Ayolas que sea en gloria. In: Desde el oriente. Documentos para la historia del Oriente boliviano y Santa Cruz la Vieja (1542-1597) (C. Julien): 50-56; Santa Cruz: Fondo Editorial Municipal.

MÉTRAUX, A., 1942 - The native tribes of Eastern Bolivia and Western Matto Grosso, 182 pp.; Washington: Bureau of American Ethnology Bulletin 134.

MINCHIN, J. B., 1881 - Eastern Bolivia and the Gran Chaco. Proceedings of the Royal Geographical Society and Monthly Record of Geography, New Monthly Series, Vol. 3, n. ${ }^{\mathbf{7}}$ 7: 401-420.

NORDENSKIÖLD, E., 2001 [1924] - Exploraciones y aventuras en Sudamérica, 438 pp.; La Paz: Apoyo Para el Campesino-Indígena del Oriente Boliviano (Apcob).

NORDENSKIÖLD, E., 2003 [1922] - Indios y blancos en el nordeste de Bolivia, 239 pp.; La Paz: Apoyo Para el Campesino-Indígena del Oriente Boliviano (Apcob).

ORBIGNY, A. d', 1944 [1839] - El hombre americano. Considerado en sus aspectos fisiológicos y morales, 402 pp.; Buenos Aires: Futuro.

ORBIGNY, A. d', 2002 - Viaje a la América Meridional. Brasil - Uruguay - Argentina Chile - Bolivia - Perú, 4 tomos, 1763 pp.; La Paz: Instituto Francés de Estudios Andinos (IFEA), Plural editores, Institut de Recherche pour le Développement (IRD), Embajada de Francia en Bolivia.

PACHECO DE OLIVEIRA, J., 1998 - Uma etnología dos 'indios misturados'? Situaçao colonial, territorializaçao e fluxos culturais. Mana, 4 (1): 47-77.

RADDING, C., 2005 - Paisajes de poder e identidad: fronteras imperiales en el desierto de Sonora y bosques de la Amazonía, 442 pp.; Sucre: Archivo y Biblioteca Nacionales de Bolivia.

RELACIÓN DE LOS CASOS..., 2008 [1561] - Relación de los casos en que el capitán Ñuflo de Chaves ha servido a Su Majestad desde el año de quinientos y cuarenta. In: Desde el oriente. Documentos para la historia del Oriente boliviano y Santa Cruz la Vieja (1542-1597) (C. Julien): 66-69; Santa Cruz: Fondo Editorial Municipal.

RELACIÓN DEL P. DIEGO DE SAMANIEGO, 1944 [c. 1600] - Relación del P. Diego de Samaniego, con muchas noticias sobre misiones hechas a los itatines, chiriguanas y chiquitos. In: Historia General de la Compañía de Jesús en la Provincia del Perú. Crónica anónima de 1600 que trata del establecimiento y misiones de la Compañía de Jesús en los países de habla española en la América Meridional, Tomo II (F. Mateos S.J.): 471-507; Madrid: CSIC.

RELACIÓN VERDADERA..., 2008 [1571] - Relación verdadera del asiento de Santa Cruz de la Sierra [Cuzco 1571]. In: Desde el oriente. Documentos para la historia del Oriente boliviano y Santa Cruz la Vieja (1542-1597) (C. Julien): 212-217; Santa Cruz: Fondo Editorial Municipal.

RICHARD, N., 2011 - La querelle des noms. Chaînes et strates ethnonymiques dans le Chaco Boreal. Journal de la Societé des Américanistes, 97-2: 201-230. 
RIESTER, J., 1976 - En busca de la Loma Santa, 376 pp.; La Paz: Los Amigos del Libro.

RIESTER, J., 1986 - Zúbaka. La Chiquitanía: visión antropológica de una región en desarrollo. Tomo I, 388 pp.; La Paz: Los Amigos del Libro.

SÁNCHEZ LABRADOR, J., 1910 [1770] - El Paraguay Católico. Tomo I, 323 pp.; Buenos Aires: Imprenta de Coni Hermanos.

SOTOMAYOR, W. A., 2013 - Relaciones Brasil Bolivia. La definición de las fronteras, 247 pp.; La Paz: Biblioteca CERES, Plural.

SUMA DAS CONSULTAS..., 1955 - Suma das consultas celebradas nos povos de São Xavier e São Rafael sobre a possibilidade de reduzir a 3 os 6 povos da missão dos chiquito. In: Antecedentes do tratado do Madri. Jesuitas e bandeirantes no Paraguay (1703-1751) (J. Cortesão, ed.): 114-129; Río de Janeiro: Biblioteca Nacional.

SUSNIK, B., 1968 - Chiriguanos I. Dimensiones etnosociales, 269 pp.; Asunción: Museo Etnográfico Andrés Barbero.

SUSNIK, B., 1978 - Los aborígenes del Paraguay I. Etnología del Chaco Boreal y su periferia (siglos XVI y XVIII), 156 pp.; Asunción del Paraguay: Museo Etnográfico Andrés Barbero.

THIELE, G. \& NOSTAS, M., 1994 - Los chiquitanos del sureste: marginalización y diferenciación. América Indígena, 3 - LIV: 9-37.

TOMICHÁ CHARUPÁ, R., 2002 - La primera evangelización en las reducciones de Chiquitos, Bolivia (1691-1767). Protagonistas y metodología misional, 739 pp.; Cochabamba: Verbo Divino, Ordo Fratum Minorum Conv., Universidad Católica Boliviana.

TOMICHÁ CHARUPÁ, R., 2006 - La formación sociocultural de los chiquitanos en el oriente boliviano (siglos XVI-XVIII). Anuario de Estudios Bolivianos, Archivísticos y Bibliográficos, 12: 631-665.

TOMICHÁ CHARUPÁ, R., 2008 - Francisco Burgués y las misiones de Chiquitos. El memorial de 1703 y documentos complementarios, 218 pp.; Cochabamba: Instituto Latinoamericano de Misionología, Editorial Verbo Divino.

VAUDRY, J.-B., 1908 - En el Oriente Boliviano. Notas sobre las provincias de Chiquitos y Velasco, traducido del francés por P. Blanco. Revista del Ministerio de Agricultura y de Colonizacion de Bolivia, 37-38-39: 228-235.

VILLAR, D. \& COMBÈS, I., 2012 - Introducción: una aproximación comparativa a las tierras bajas bolivianas. In: Las tierras bajas de Bolivia: miradas históricas y antropológicas (D. Villar \& I. Combès, eds.): 7-31; Santa Cruz de la Sierra: Museo de Historia UAGRM, El País. 